\title{
GCU
}

Glasgow Caledonian

University

University for the Common Good

\section{Upright time and sit-to-stand transition progression after total hip arthroplasty: an in- hospital longitudinal study}

Jeldi, Artaban Johnson; Grant, Margaret; Allen, David J.; Deakin, Angela H.; McDonald, David; Stansfield, Ben W.

Published in:

Journal of Arthroplasty

DOI:

10.1016/j.arth.2015.09.024

Publication date:

2016

Document Version

Author accepted manuscript

Link to publication in ResearchOnline

Citation for published version (Harvard):

Jeldi, AJ, Grant, M, Allen, DJ, Deakin, AH, McDonald, D \& Stansfield, BW 2016, 'Upright time and sit-to-stand transition progression after total hip arthroplasty: an in-hospital longitudinal study', Journal of Arthroplasty, vol. 31, no. 3, pp. 735-739. https://doi.org/10.1016/j.arth.2015.09.024

\section{General rights}

Copyright and moral rights for the publications made accessible in the public portal are retained by the authors and/or other copyright owners and it is a condition of accessing publications that users recognise and abide by the legal requirements associated with these rights.

Take down policy

If you believe that this document breaches copyright please view our takedown policy at https://edshare.gcu.ac.uk/id/eprint/5179 for details of how to contact us. 
Title: Upright time and sit-to-stand transition progression following total hip arthroplasty: An in-hospital longitudinal study

Artaban Johnson Jeldi ${ }^{\mathrm{a}}$ MPT (artaban.johnson@gcu.ac.uk)

Margaret Grant ${ }^{\mathrm{a}}, \mathrm{PhD}$ (M.grant@gcu.ac.uk)

David Allen ${ }^{\text {b }}$, FRCSEd (Trauma \& Orthopaedics) (David.Allen@ginh.scot.nhs.uk)

Angela.H. Deakin ${ }^{\text {b PhD (Angela.Deakin@gjnh.scot.nhs.uk) }}$

David McDonald ${ }^{\mathbf{b}}$ ProfD (david.mcdonald@nhs.net)

Ben Stansfield ${ }^{\mathrm{a}} \mathrm{PhD}$ (ben.stansfield@gcu.ac.uk)

\section{Authors: Address}

a) Institute for Applied Health Research, Glasgow Caledonian University, Glasgow, UK G4 OBA.

b) Department of Orthopaedics, Golden Jubilee National Hospital, Clydebank, Glasgow, UK. G81 4DY

\section{Corresponding Author}

Mr Artaban Jeldi,

School of Health and Life Sciences, Glasgow Caledonian University, UK

Tel: 00 (44) 1413313466

E-mail: artaban.johnson@gcu.ac.uk 


\section{Acknowledgements}

The Authors would like to thank all the patients who participated in the study. Special thanks to the Ward and Rehabilitation staff at the Golden Jubilee National Hospital, NHS Scotland. Special Thanks to Prof Malcolm Granat for his input in the Study. This Study was funded internally within Glasgow Caledonian University as part of a PhD Studentship. 


\section{Abstract}

Background:

Whilst early mobilization in-hospital is a key element of post-total hip replacement (THR) rehabilitation, it is poorly documented.

Methods:

To gain quantitative insight into in-hospital mobilization upright times and sit-to-stand transitions were measured using a thigh-mounted movement sensor in forty four participants (13M;31F), age 50-82y, in an observational, post-surgery, in-hospital, longitudinal study.

Results:

Some participants performed no activity in the first $24 \mathrm{hrs}$ following surgery. However, in the last $24 \mathrm{hrs}$ before discharge participants performed a median of 40 (IQR:15) sit-to-stand transitions and spent 134mins (IQR:74mins) upright. Activity in rehabilitation constituted 19.4\% (IQR:15.8\%) of sit-to-stand transitions and 13.3\% (IQR:5.5\%) of upright time. Females spent longer in-hospital (80hrs IQR:24) compared to males (54hrs IQR:26).

Conclusion:

Whilst there was considerable activity within rehabilitation periods a large majority of sit-tostand transitions and upright time occurred outside rehabilitation. Within the Last $24 \mathrm{hrs}$ inhospital all participants were upright for prolonged periods and completed numerous sit-tostand transitions.

Key words: Physical activity, Sit-to-stand transitions, Upright time, Total Hip Arthroplasty, Rehabilitation. 
1 Title: Upright time and sit-to-stand transition progression following total hip arthroplasty: An

2 in-hospital longitudinal study

3

4 Abstract

5 Background:

6 Whilst early mobilization in-hospital is a key element of post-total hip replacement (THR)

7 rehabilitation, it is poorly documented.

8 Methods:

9 To gain quantitative insight into in-hospital mobilization upright times and sit-to-stand transitions were measured using a thigh-mounted movement sensor in forty four participants

11 (13M;31F), age 50-82y, in an observational, post-surgery, in-hospital, longitudinal study.

12 Results:

13 Some participants performed no activity in the first $24 \mathrm{hrs}$ following surgery. However, in the 14 last 24hrs before discharge participants performed a median of 40 (IQR:15) sit-to-stand 15 transitions and spent 134mins (IQR:74mins) upright. Activity in rehabilitation constituted $1619.4 \%$ (IQR:15.8\%) of sit-to-stand transitions and 13.3\% (IQR:5.5\%) of upright time. Females 17 spent longer in-hospital (80hrs IQR:24) compared to males (54hrs IQR:26).

18 Conclusion:

19 Whilst there was considerable activity within rehabilitation periods a large majority of sit-to20 stand transitions and upright time occurred outside rehabilitation. Within the Last $24 \mathrm{hrs}$ in21 hospital all participants were upright for prolonged periods and completed numerous sit-to22 stand transitions.

\section{Keywords}

24 Physical activity, Sit-to-stand transitions, Upright time, Total Hip Arthroplasty, Rehabilitation. 


\section{List of Abbreviations}

ASA American Society of Anesthesiologists Physical Status Classification

ERP Enhanced recovery programme

29 IQR Inter-quartile range

30 OT Occupational therapy

31 PA Physical activity

32 PT Physiotherapy

33 STS Sit to stand transitions

34 THA Total hip Arthroplasty

35 VAS Visual analogue scale

\section{INTRODUCTION}

Total hip arthroplasty surgery (THA) is performed to eliminate pain and improve function [1]-

39 [3]. The process of rehabilitation to increase mobility and improve function starts whilst in

40 hospital. The resumption of sit-to-stand transitions (STS) and engagement in upright activities

41 are indicators of recovery. By monitoring these activities, it is possible to quantify

42 improvement across the recovery time-line.

44 Healthcare organizations in the UK are increasingly adopting enhanced recovery programmes 45 (ERP), optimizing patient recovery, with in-hospital rehabilitation aimed to return patients to 46 independent performance of functional tasks. These programmes minimize time taken to 47 recover by tailoring pain reduction medication to allow early rehabilitation and mobilization $48[4]-[6]$. 
50 Pre- and post-THA physical activity (PA) outcomes have been reported previously [7], [8].

51 However, in-hospital activity has not been reported. This lack of quantitative evidence

52 prevents informed discussion of the efficacy of therapy programmes and physical mobility

53 promotion protocols. Objective measurement of PA would provide evidence to inform and 54 evaluate rehabilitation programmes.

The aim of this study was to answer two questions: Firstly, what are the profiles of upright time and STS in-hospital following THA and secondly, is there a difference in these profiles between males and females?

\section{MATERIALS AND METHODS}

This was an observational, in-hospital, longitudinal study of upright time and STS following THA. Ethical approval was obtained from the West of Scotland Research Ethics Committee (12/WS/0098;13/WS/0302) before commencement. All participants gave written informed consent.

Participants were recruited consecutively within two time periods from patients undergoing

THA from a single arthroplasty centre. Exclusions included; revision hip arthroplasty, previous total hip/knee arthroplasty in the last 6 months, severe locomotor limitations due to cardiopulmonary, central or peripheral nervous system deficits and spinal conditions or diagnosed 71 terminal disease. 
73 To characterise the population taking part in the study pre-operative assessments were

74 performed. These included patient and clinician based assessment; the American Society of

75 Anethesiologists Physical Status Classification (ASA) [9], Oxford Hip Score [10], Harris Hip

76 Score [11] and EQ-5D (EuroQol), both index and visual analogue scale (VAS) [12]. Capability of

77 participants was assessed using hip muscle strength (using a hand held dynamometer to

78 measure hip flexion and abduction) [13], walking speed (10m walk test, speed over middle

$796 \mathrm{~m}$ ) [14], walking endurance (six minute walk test) [15] and ability to rise from and return to a

80 chair (timed up and go test) [16]. In addition demographic data were collected from the

81 patient records.

82

83 All participants were operated on by a single consultant surgeon (DA) (or trainee under

84 supervision). Exeter ${ }^{\circledR}$ femoral component and either Contemporary ${ }^{\circledR}$ cemented cup or

85 Trident $^{\circledR}$ uncemented cup with an X3 polyethylene liner (Stryker Orthopaedics ${ }^{\mathrm{a}}$, Michigan,

86 USA) were inserted using a posterior approach. Peri-operative care (from pre-assessment

87 through discharge), following the institution's ERP [6], was aimed at promoting safe

88 independent mobility and discharge as quickly as possible. The standardized procedure within

89 the hospital at the time was: operations were carried out under spinal anesthesia with

90 sedation as required; Local intra-articular infiltration was used in theatre with $180 \mathrm{ml}$ of $0.2 \%$

91 ropivacaine injected into the joint; Post-operative analgesia included strong opiod (oxycodone

92 or fentynal transdermal patches) with PRN oxynorm and tramadol; Post-operative epidural

93 catheters were not used. 
Rehabilitation in-hospital included both physiotherapy (PT) and occupational therapy (OT).

From the day of surgery (day 0) a physiotherapist regularly assessed the participants' blood pressure, muscle power (myotomes) and sensation (dermatomes). When sensory and motor functions had returned to both lower limbs, mobilisation started from bed to chair with wheeled walking frame and assistance of two staff. Progression was made to either elbow crutches or walking sticks and to independent walking. Walking practice was complemented with exercise programmes, to strengthen and stretch the hip/knee, and to aid gait-retraining. Participants practiced stairs, mimicking their home environment, to ensure safety prior to discharge. Participants were seen, on average, twice a day by PT for 15-30mins. Participants who were successfully mobilised on day 0 started OT on day 1 , otherwise when deemed fit by the Occupational Therapist. OT was function based, focusing on activities of daily living (personal care tasks, transfers, domestic tasks). Once participants had achieved essential functional tasks necessary for activities of daily living, they were discharged from OT. Postoperative treatment time within OT was approximately once/day for $\sim 30$ mins.

\section{Outcome measures}

The primary in-hospital outcomes were upright time, the number of STS (performance of posture changes), and the longest upright bout (longest period the upright posture was maintained). Secondary outcomes were time in-hospital to discharge from rehabilitation and ward and any post-operative side-effects. Post-operative side-effects, such as nausea and vomiting, that could have affected ability to mobilize and therefore to complete the rehabilitation criteria were collected from the patient case notes. 
118 Primary in-hospital outcomes were measured objectively using a physical activity monitor

119 (activPAL3 $^{\mathrm{TM}}$, PAL Technologies Ltd ${ }^{\mathrm{b}}$. Glasgow, UK, version 7.1.18, 50x35x7mm, 30g). The

120 original activPAL ${ }^{\mathrm{TM}}$ has proven validity for the measurement of upright times and upright

121 events in adults [17] and older adults [18], [19]. Within 4hrs of participant return to ward (still

122 in bed), the monitor was attached to the anterior aspect of the thigh of the non-operated leg

123 using a waterproof surgical dressing (Duoderm extra thin hydrocolloid dressing (Convatec) or

124 Opsite flexifix (Smith \& Nephew)), for $24 \mathrm{hr} /$ day wear. Data was collected continuously for the 125 entire post-operation, in-hospital period.

126

127 In-hospital outcomes were calculated from the activePAL data using custom software for the

128 following time periods:

129 - Total: The entire post-surgery in-hospital stay.

130 - First 24hrs: The first 24hrs after monitor application to characterise initial activity post-

$131 \quad$ surgery.

132

- Last 24hrs: The last 24hrs before discharge from PT/OT, to attempt to characterise the maximum activity within a $24 \mathrm{hr}$ period in-hospital.

- Rehabilitation: The time associated with PT/OT. It was assumed that activity within the 30mins preceding the logging of the end point of PT/OT was 'associated' with rehabilitation. This approximation was made based on verbal feedback from PT/OT about the typical length of therapy. The \% of total activity associated with PT/OT was

139 Secondary outcomes were collected from the patient records. 
142 Not all data sets were normally distributed (Shapiro Wilk), therefore, to maintain consistency

143 analysis was performed using non-parametric statistics. Median, interquartile range and

$144 \mathrm{~min} / \mathrm{max}$ values describe outcomes. A comparison of male and female outcomes was made

145 (Mann Whitney U test). A point estimate (95\% confidence interval) of the difference between

146 gender outcomes was calculated. A significance level of $p<0.05$ was used (Minitab 17, Minitab

147 Inc.).

148

\section{RESULTS}

150 Fifty (16M/34F) participants were recruited from 125 patients (Figure 1) undergoing THA.

151 Complete data sets were recorded from 44 participants (13M/31F), median age 68y (50-82)

152 and median BMI $29.7 \mathrm{~kg} / \mathrm{m}^{2}$ (23.2-43.3) (Table 1). All participants were of Scottish White

153 origin.

154

155 Pre-operatively there were no statistically significant differences between male and female

156 participants in ASA, Oxford Hip Score, Harris Hip Score or the EQ-5D Index or VAS ( $p \geq 0.219)$

157 (Table 1). However, males had stronger hip flexors (median difference 5.7N, 95\% Cl: 1.3,10.4;

$158 \mathrm{p}=0.012$ ) and abductors (median difference $3.7 \mathrm{~N}, 95 \% \mathrm{Cl}: 1.2,5.7 ; \mathrm{p}=0.002$ ) than females and

159 performed the timed up and go test faster (median difference $-2.7 \mathrm{~s}, 95 \% \mathrm{Cl}:-5.2,-0.2$;

$160 \mathrm{p}=0.035$ ). Whilst males tended to walk faster over the $10 \mathrm{~m}$ walk test (median difference -

$1610.18 \mathrm{~m} / \mathrm{s}, 95 \% \mathrm{Cl}:-0.10,0.48 ; \mathrm{p}=0.208)$ and travel further during the six minute walk test

162 (median difference $56 \mathrm{~m}, 95 \% \mathrm{Cl}:-6,120 ; \mathrm{p}=0.070$ ) than females these differences were not

163 statistically significant. 
Discharge from rehabilitation (PT/OT) occurred at 68hrs (IQR:24) with discharge from hospital at 74hrs (IQR:25) (Table 2).

Overall during the first $24 \mathrm{hrs}$ after return to ward there was considerable variation in the STS (0-61), total upright time (0-232mins) and longest upright bout (0-68mins) (Table 2). There continued to be similar high levels of variation in outcomes in the last $24 \mathrm{hrs}$ before discharge with 18-78 STS, 51-429mins of upright time and a longest upright bout of between 5-85mins. Time in-hospital and the time spent upright varied widely (Figure 2). Additionally side-effects of operation were noted (Figure 2). Overall 19.4\% (IQR:15.8) of the total number of STS and 13.3\% (IQR:5.5) of upright time was associated with rehabilitation time (Table 2).

Females stayed a median of $20 \mathrm{hrs}(95 \% \mathrm{Cl}: 0-25)(42 \%)(p=0.035)$ longer in hospital to the point of discharge from therapy than males and $22 \mathrm{hrs}(95 \% \mathrm{Cl}: 3-37)(41 \%)(\mathrm{p}=0.008)$ longer to discharge from the ward. In the first $24 \mathrm{hrs}$ following return to ward males had more STS (95\%Cl:5-14) $(p<0.001)$, longer total upright time (95\%Cl:18-61mins) $(P<0.001)$ and longer longest upright bout (95\%Cl:1-13mins) $(P=0.007)$ (Table 2) than females. However, in the $24 \mathrm{hrs}$ before discharge there was only a statistical difference in the longest upright bout with males having longer bouts than females ( $95 \% \mathrm{Cl}: 1-17 \mathrm{mins})(p=0.037)$. Side-effects were noted for only $1 / 13$ males, but for $17 / 31$ females (Figure 2 ).

\section{DISCUSSION}

This is the first report of in-hospital PA following THA and provides insight into typical activity following operation. This objective analysis highlighted the considerable volume of activity performed both within and outside of rehabilitation sessions and the considerably slower 
recovery of females compared to males. The age, OHS and self-reported quality of life (EQ-5D

190

191 across the UK [20]

192

193

In the first $24 \mathrm{hrs}$ post-surgery some participants remained in bed, usually due to slow recovery from anesthesia. Side-effects that limited the implementation of therapy included low blood pressure, nausea, vomiting and individual specific health problems. The change between the first $24 \mathrm{hrs}$ after surgery and the last $24 \mathrm{hrs}$ before discharge reflects several factors including recovery from anesthesia, efficacy of pain medication and rehabilitation participation. Within the last $24 \mathrm{hrs}$ higher PA levels were achieved with a median of 40 STS and 134mins upright. However, there was a large variation in outcomes (Figure 2), perhaps reflecting personal choice. Within the $24 \mathrm{hrs}$ before discharge the longest upright bouts were considerable (5-85mins) demonstrating the possibility of extended periods of standing for most participants. Whilst STS and upright time post-THA in-hospital do not appear to have been previously reported, these outcomes have been reported ( $12 \mathrm{hr} /$ day) for older adults admitted to day hospital (230mins upright, $57 \mathrm{STS} / 12 \mathrm{~h}$ ), older adults admitted to a ward for rehabilitation (79mins upright, $36 \mathrm{STS} / 12 \mathrm{~h}$ ) and an age matched ( $74 \pm 6 \mathrm{y}$ ) healthy population (360mins upright, 71 STS/12h)[21], [22]. In the current study participants had levels above those admitted to a ward for rehabilitation, but lower than those admitted to a day hospital.

Rehabilitation accounted for almost $20 \%$ of STS and $13 \%$ of the total upright time, demonstrating there was considerable activity within these periods, yet the majority of PA was completed by personal choice (or necessity) outside the formal rehabilitation sessions. This must be considered when developing motivational strategies for encouraging PA within 
hospital. As part of the ERP participants were encouraged by the multidisciplinary team

214 (surgeon, PT/OT, nurses) to be as active as possible, getting up and walking around. Previous

215 research with different patient groups has demonstrated the effectiveness of a multi-

216 disciplinary team approach to in-patient rehabilitation [23]-[25]. This may be one reason for

217 the relatively large proportions of STS ( $80 \%)$ and upright time ( $85 \%)$ outside rehabilitation.

219 Females were slower to mobilize and tended to lag behind males' activity by $\sim 24 \mathrm{hrs}$, giving

220 longer time to the point of discharge from rehabilitation (females' median 69hrs; males'

221 median 48hrs). Within this cohort females had a much higher incidence of nausea and

222 vomiting, low blood pressure or tiredness (Figure 2). It is clear that these factors may have

223 delayed the initiation of or temporarily stopped rehabilitation ultimately leading to a longer

224 stay in hospital. However, based on the results collected for this study it was not possible to

225 determine if there was a causal relationship between these factors.

227 The samples of male and female participants studied had similar pre-operative self and

228 clinician-assessed scores. However, before surgery males were stronger and were able to 229 perform the timed-up and go test faster than females. Males and females did have similar

230 speed of walking and endurance. It is possible that these differences in strength and ability to

231 perform the standing and turning movements were critical in determining the course of

232 recovery allowing males to engage with activity earlier than females. However, it is clear that

233 limitations in pre-operative hip strength and ability to stand from a sitting posture were not

234 great enough to prevent locomotion. Perhaps in conjunction with weakness caused by tissue

235 disruption during surgery, the lower levels of strength and capacity in females may have

236 limited early activity engagement. 
238 This study has a number of limitations. Participants were recruited from one hospital under

239 the care of one surgeon possibly limiting generalizability. Characterisation of activity

240 associated with PT/OT used an assumption about the time period of analysis. This could have

241 led to an overestimation of the activity associated with rehabilitation. Post-operative side-

242 effects were more frequent for the females than males, which may have caused differences in

243 outcomes. However, this study was not powered to systematically investigate this effect.

CONCLUSION

This is the first study to quantify upright time and sit-to-stand transitions in-hospital following

THA. The objective outputs reported here, as derived from a body-worn sensor, reveal that

patients are performing considerable activity both within rehabilitation sessions and outside

of these times. The values obtained here for the outcome measures can be used as reference

values for further research. This analysis provides invaluable insight into patients' response to the rehabilitation regime and recovery post-THA.

\section{REFERENCES}

[1] I. D. Learmonth, C. Young, and C. Rorabeck, "The operation of the century: total hip

[2] D. Monaco, F. Vallero, R. Tappero, and A. Cavanna, "Rehabilitation after THR : A systematic review of Controlled trails on physical excercise programs," Eur. J. Phys. Rehabil. Med., vol. 45, no. 3, pp. 303-317, 2009.

[3] P. Kuijer, M. de Beer, J. Houdijk, and M. Frings-Dresen, "Beneficial and limiting factors affecting return to work after total knee and hip arthroplasty: a systematic review.," J. 
[4] L. Basse, D. Hjort Jakobsen, P. Billesbølle, M. Werner, and H. Kehlet, "A clinical pathway to accelerate recovery after colonic resection.," Ann. Surg., vol. 232, no. 1, pp. 51-7, Jul. 2000.

[5] A. Malviya, K. Martin, I. Harper, D. Muller, P. Emmerson, F. Partington, and R. Reed, "Enhanced recovery program for hip and knee replacement reduces death rate.," Acta Orthop., vol. 82, no. 5, pp. 577-582, Oct. 2011.

[6] D. McDonald, R. Siegmeth, A. Deakin, A. W. G. Kinninmonth, and N. B. Scott, "An enhanced recovery programme for primary total knee arthroplasty in the United

[7] M. M. Vissers, J. B. Bussmann, I. B. De Groot, J. A. N. Verhaar, and M. Reijman, "Gait \&

[8] I. B. de Groot, H. J. Bussmann, H. J. Stam, and J. a Verhaar, "Small increase of actual

[9] M. Daabiss, "American society of anaesthesiologists physical status classification," Indian Journal of Anaesthesia, vol. 55, no. 2. pp. 111-115, 2011.

[10] V. Wylde, I. D. Learmonth, V. J. Cavendish, E. V. W. Vwyldebristolacuk, I. D. L. lanlearmonthbristolacuk, and V. J. C. Vjcavendishbristolacuk, "The Oxford hip score : the patient 's perspective," Health Qual. Life Outcomes, vol. 8, pp. 1-8, 2005.

[11] P. Söderman and H. Malchau, "Is the Harris hip score system useful to study the outcome of total hip replacement?," Clin. Orthop. Relat. Res., no. 384, pp. 189-97, Mar. 2001.

[12] E. Nord, "EuroQol: health-related quality of life measurement. Valuations of health states by the general public in Norway.," Health Policy, vol. 18, pp. 25-36, 1991.

[13] W. Andrews, M. Thomas, and R. Bohannon, "Normative values for isometric muscle force measurements obtained with hand-held dynamometers.," Phys. Ther., vol. 76, no. 3, pp. 248-59, Mar. 1996.

[14] R. W. Bohannon, a W. Andrews, and M. W. Thomas, "Walking speed: reference values and correlates for older adults.," J. Orthop. Sports Phys. Ther., vol. 24, no. 2, pp. 86-90, 1996.

[15] R. Rikli and J. Jones, "The Reliability and Validity of a 6 Minute Walk as a measure of physical endurance in older adults," J. Aging Phys. Act., vol. 6, pp. 363-375, 1998.

[16] M. Pondal and T. del Ser, "Normative data and determinants for the timed 'up and go' test in a population-based sample of elderly individuals without gait disturbances.," $J$. Geriatr. Phys. Ther., vol. 31, no. 2, pp. 57-63, Jan. 2008. 
[17] C. G. Ryan, P. M. Grant, W. W. Tigbe, and M. H. Granat, "The validity and reliability of a novel activity monitor as a measure of walking.," Br. J. Sports Med., vol. 40, no. 9, pp. 779-84, Sep. 2006.

[18] P. M. Grant, C. G. Ryan, W. W. Tigbe, and M. H. Granat, "The validation of a novel activity monitor in the measurement of posture and motion during everyday

[25] D. J. Clarke, "Multidisciplinary care The role of multidisciplinary team care in stroke rehabilitation," Stroke Rehabil., vol. 17, no. July/August, pp. 5-8, 2013.

\section{Suppliers}

${ }^{\text {a }}$ Stryker Orthopaedics, Michigan, USA: Exeter ${ }^{\circledR}$ femoral component, Contemporary ${ }^{\circledR}$

${ }^{\text {b }}$ PAL Technologies Ltd. Glasgow, UK: activPAL3 ${ }^{\text {TM }}$ 


\section{List of Figures Legends}

Figure 1

Strobe flow chart of participant recruitment.

Figure 2

All participants' upright time as a percentage of each hour (0-100\%). Twenty four hour time blocks marked as per key. First $100 \%$ line indicates start of record and last $100 \%$ line indicates end of record for each individual. Female (left) and Male (right) outcomes are illustrated ordered by age of participant (years).

Post-operative side-effects affecting mobilization: *=low blood pressure; $\$=$ nausea and vomiting; \#=other including headache, mild fracture, dizziness, vaso vagal issues, reduced confidence, delayed sensory and motor recovery, delirious and confusion, atrial fibrillation. 


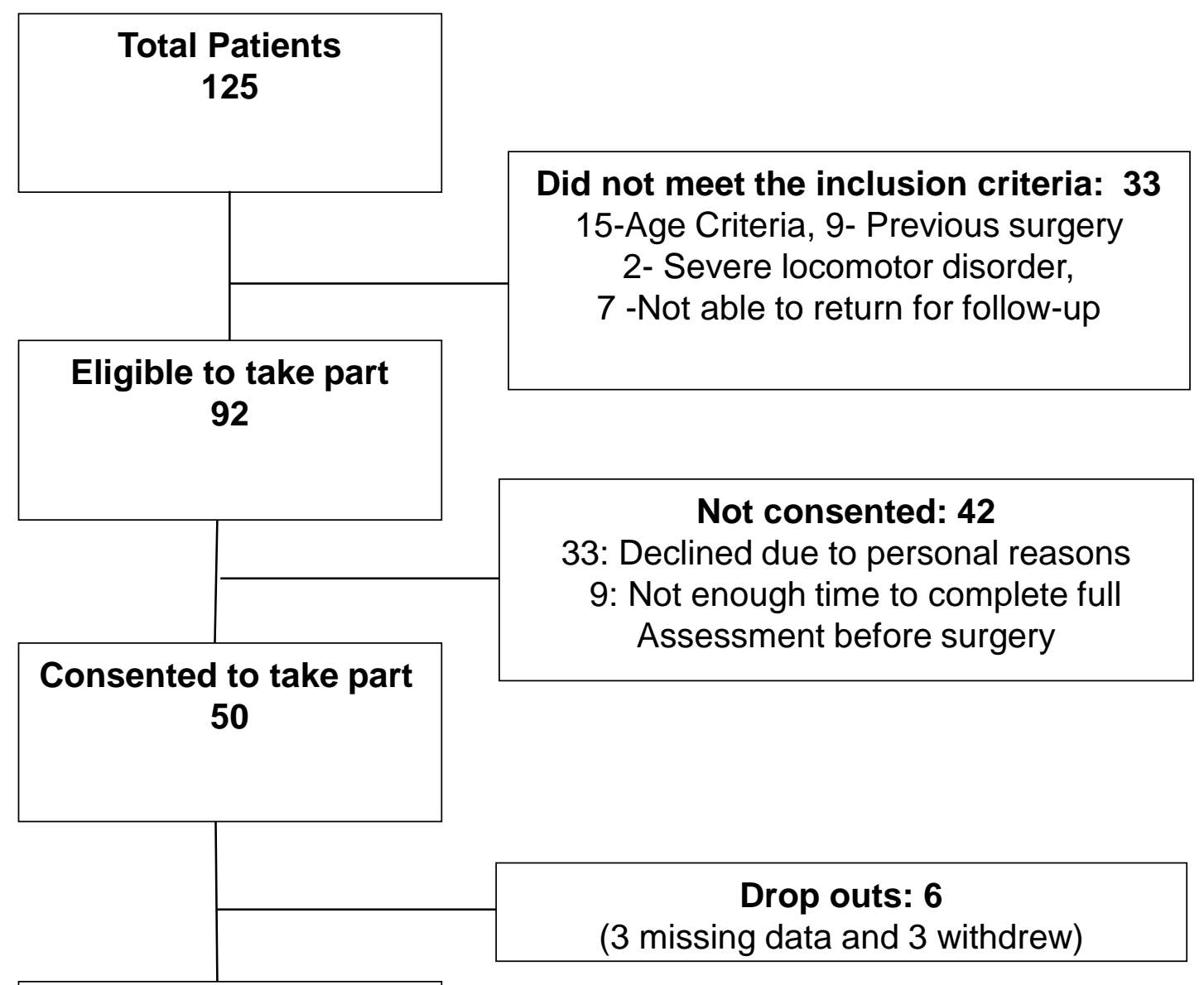

Successful data collection

44 


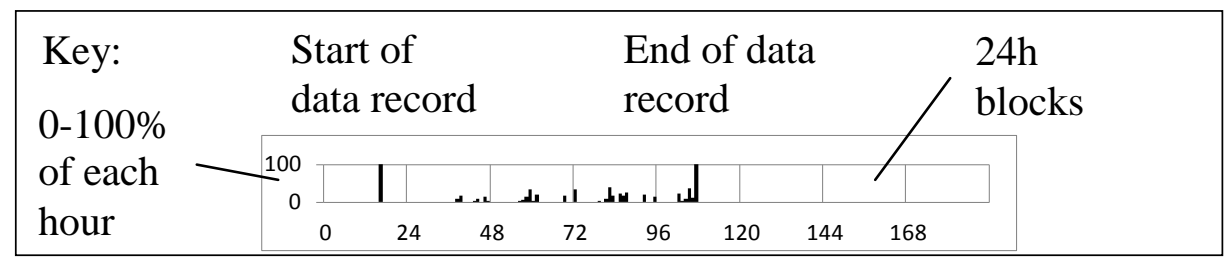

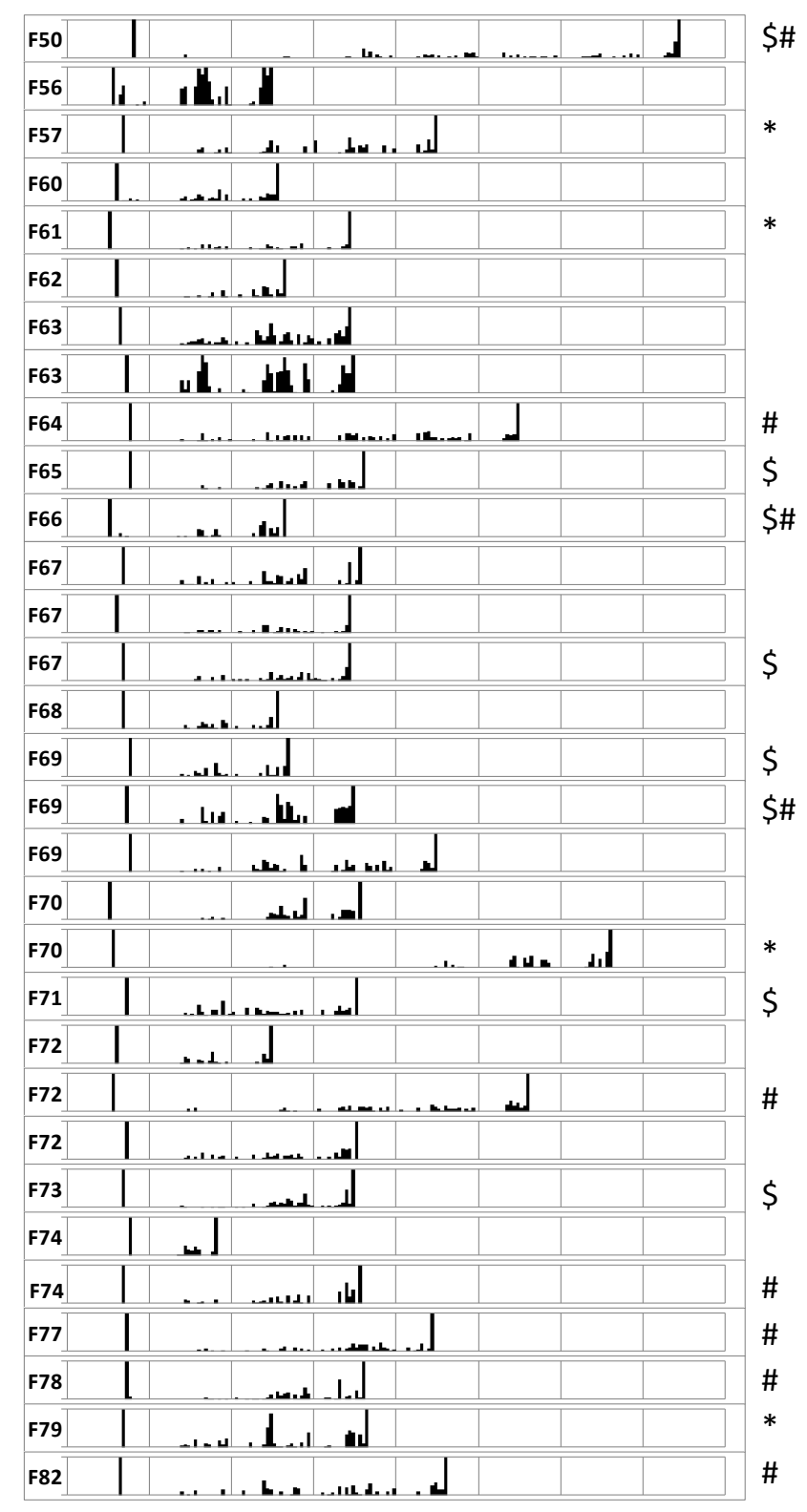

Figure $2 \quad$ All participants' upright time as a percentage of each hour (0-100\%). Twenty four hour time blocks marked as per key. First $100 \%$ line indicates start of record and last $100 \%$ line indicates end of record for each individual. Female (left) and Male (right) outcomes are illustrated ordered by age of participant (years).

Post-operative complications affecting mobilization: ${ }^{*}=$ low blood pressure; $\$=$ nausea and vomiting; \#=other including headache, mild fracture, dizziness, vaso vagal issues, reduced confidence, delayed sensory and motor recovery, delirious and confusion, atrial fibrillation. 
Table 1 Participant demographic details and pre-operative scores. Differences in outcomes between male and female are given with point estimate of difference $\left({ }^{*}\right)$ and $95 \%$ confidence interval $(\mathrm{CI})$ of the difference ( $p$-value from Mann Whitney U test). (IQR = interquartile range)

\begin{tabular}{|c|c|c|c|c|c|}
\hline & \multirow{2}{*}{$\begin{array}{l}\text { All participants (44) } \\
\text { Median (IQR) [range] }\end{array}$} & \multirow{2}{*}{$\begin{array}{c}\text { Male (13) } \\
\text { Median (IQR) [range] }\end{array}$} & \multirow{2}{*}{$\begin{array}{c}\text { Female (31) } \\
\text { Median (IQR) [range] }\end{array}$} & \multicolumn{2}{|c|}{ Male-Female difference } \\
\hline & & & & Difference $^{*}(95 \% \mathrm{Cl})$ & p-value \\
\hline Age (years) & $68(9)[50-82]$ & $65(8)[57-78]$ & $69(9)[50-82]$ & $-2(-6,4)$ & 0.562 \\
\hline Height $(m)$ & $1.65(0.12)[1.50-1.82]$ & $1.73(0.05)[1.54-1.82]$ & $1.62(0.09)[1.50-1.73]$ & $0.11(0.07,0.15)$ & $<0.001$ \\
\hline Weight $(k g)$ & $81.5(23.5)[60.0-132.6]$ & 93.0 (14.4) 74.5-132.6] & 71.0 (17.5) [60.0-120.4] & $20.1(11.6,28.6)$ & 0.001 \\
\hline \multicolumn{6}{|l|}{ Pre-operative scores } \\
\hline ASA & $2(0)[2-3]$ & $2(0)$ [2-3] & $2(0)[2-3]$ & $0(0,0)$ & 0.607 \\
\hline Oxford Hip Score (48) & $16(7)[5-42]$ & 17 (6) [8-22] & 15 (7) [5-42] & $0(-5,4)$ & 0.928 \\
\hline EQ-5D-5L Index (1.000) & $0.341(0.251)[-0.080-0.698]$ & $0.345(0.300)$ [0.081-0.604] & $0.336(0.258)[-0.080-0.698]$ & $0.052(-0.094,0.195)$ & 0.528 \\
\hline EQ-5D-5L VAS (100) & $55(33)[10-100]$ & 60 (25) [30-95] & $50(35)[10-100]$ & $10(-5,25)$ & 0.219 \\
\hline Hip flexion strength $(N)$ & 56.4 (38.2) [23.6-129.3] & $73.4(46.5)$ [30.5-124.9] & $53.1(27.1)$ [23.6-129.3] & $5.7(1.3,10.4)$ & 0.012 \\
\hline Hip abduction strength $(M)$ & $46.3(20.5)$ [18.2-113.9] & $54.3(12.0)$ [30.3-113.9] & $38.8(21.0)[18.2-63.2]$ & $3.7(1.2,5.7)$ & 0.002 \\
\hline $10 \mathrm{~m}$ walk test $(\mathrm{m} / \mathrm{s})$ & $0.95(0.51)[0.38-2.30]$ & $1.03(0.63)[0.38-2.30]$ & $0.92(0.52)[0.38-1.73]$ & $0.18(-0.10,0.48)$ & 0.208 \\
\hline Six minute walk test $(m)$ & 264 (137) [105-476] & 330 (144) [153-476] & 243 (122) [105-421] & $56(-6,120)$ & 0.070 \\
\hline Timed up and go test ( $s$ ) & $13.5(5.4)[7.8-27.3]$ & $11.7(3.8)[8.3-24.6]$ & $14.6(4.9)[7.8-27.3]$ & $-2.7(-5.2,-0.2)$ & 0.035 \\
\hline
\end{tabular}

ASA=American Society of Anesthesiologists Physical Status Classification

VAS=visual analogue scale outcome 
Table 2 In-hospital durations and physical activity outcomes for all participants and for males and females. Differences in outcomes between males and females are given with point estimate of difference $\left(^{*}\right)$ and $95 \%$ confidence interval $(\mathrm{Cl})$ of the difference $(p$-value from Mann Whitney U test). (Rehab = rehabilitation; STS = sit-to-stand transitions; D/c = discharge, IQR = interquartile range)

\begin{tabular}{|c|c|c|c|c|c|c|}
\hline & & All participants (44) & Male (13) & Female (31) & \multicolumn{2}{|c|}{ Male-Female difference } \\
\hline & Outcome & Median (IQR) [range] & Median (IQR) [range] & Median (IQR) [range] & Difference $^{*}(95 \% \mathrm{Cl})$ & $p$-value \\
\hline \multirow[t]{2}{*}{ Time to discharge } & D/c from Ward (hrs) & 74 (25) [44-188] & $54(26)[45-94]$ & 80 (24) [44-188] & $-22(-37,-3)$ & 0.008 \\
\hline & D/c from Rehab (hrs) & $68(24)[21-160]$ & $48(25)[42-73]$ & 69 (15) [21-160] & $-20(-25,0)$ & 0.035 \\
\hline \multirow{3}{*}{$\begin{array}{l}\text { First } 24 \text { hours after } \\
\text { operation }\end{array}$} & STS & $9(8)[0-61]$ & $16(9)[6-61]$ & $8(6)[0-27]$ & $9(5,14)$ & $<0.001$ \\
\hline & Total Upright (mins) & 25 (37) [0-232] & 66 (47) [16-232] & $14(21)$ [0-199] & $40(18,61)$ & $<0.001$ \\
\hline & Longest upright bout (mins) & $7(6)[0-68]$ & $10(15)[4-45]$ & $6(4)[0-68]$ & $6(1,13)$ & 0.007 \\
\hline \multirow{3}{*}{$\begin{array}{l}\text { Last } 24 \text { hours } \\
\text { before } D / c\end{array}$} & STS & 40 (15) [18-78] & 40 (15) [18-78] & 40 (16) [21-72] & $2(-6,11)$ & 0.728 \\
\hline & Total Upright (mins) & $134(74)$ [51-429] & 169 (77) [71-420] & 132 (47) [51-429] & $33(-11,74)$ & 0.165 \\
\hline & Longest upright bout (mins) & $16(17)[5-85]$ & $27(13)[5-78]$ & $14(10)[7-85]$ & $10(1,17)$ & 0.037 \\
\hline \multirow[t]{2}{*}{ Rehab activity } & STS & 16 (12) [7-38] & $17(12)[7-34]$ & $16(12)[7-38]$ & $0(-5,6)$ & 0.990 \\
\hline & Total Upright (mins) & $39(24)[11-141]$ & 41 (31) [17-86] & $36(25)[11-141]$ & $7(-9,20)$ & 0.368 \\
\hline \multirow[t]{2}{*}{ (\% of total) } & STS (\%) & $19.4(15.8)[5.3-43.4]$ & $23.1(8.8)[15.2-30.8]$ & $17.9(21.7)[5.3-43.4]$ & $2.4(-6.6,8.7)$ & 0.537 \\
\hline & Total Upright (\%) & $13.3(5.5)[3.5-40.2]$ & $12.8(2.9)[8.1-19.4]$ & $13.9(8.8)[3.5-40.2]$ & $0.2(-3.4,3.8)$ & 0.918 \\
\hline
\end{tabular}

